\title{
Momentum Budget over the Pyrénées: The PYREX Experiment
}

\author{
P. Bougeault, ${ }^{*}$ A. Jansa Clar, ${ }^{+}$B. Benech, ${ }^{*}$ \\ B. Carissimo, ${ }^{* *}$ J. Pelon, ${ }^{+\dagger}$ and E. Richard ${ }^{\# \#}$
}

\section{Abstract}

Although the qualitative influence of mountains over the atmosphere has been known for a long time, numerous deficiencies, linked to orography, are still noted, either in forecasts by regional models, or in the long-term behavior of climate models. This is why the French and Spanish weather services are undertaking an important field campaign to document the dynamic modifications to the atmospheric flow generated by the Pyrenean range during a 2-month period (October and November 1990) with six intensive observation periods (IOPs) of 2 to 3 days. The experimental strategy is based largely on mesoscale numerical-model results and will help to validate these models. The main focus is on the documentation of clear-air turbulence generated either by breaking mountain waves, by surface roughness, or by the wind shear induced by the lateral-flow deviation around the mountain. Experimental means include several networks of surface stations, radio soundings, constant-level balloons, four wind profilers, and several research aircraft.

\section{Introduction}

The Momentum Budget over the Pyrénées (PYREX) experiment is a joint program by the French and Spanish Weather services: Direction de la Météorologie (DMN/EERM) and Instituto Nacional de Meteorologia (INM). It is made possible by the participation of several research institutes from France, Spain, and Germany: Centre National de Recherches Météorologiques (CNRM), Electricité de France (EDF/DER), Laboratoire de Métérologie Physique (LAMP), Laboratoire d'Aérologie (LA), Laboratoire de Météorologie Dynamique (LMD), Service d'Aéronomie (SA), La-

\footnotetext{
* Centre National de Recherches Météorologiques, DMN/ EERM, 31057 Toulouse, France

${ }^{+}$Centro Meteorologico Zonal de Baleares, INM, 07015 Palma de Mallorca, Spaine

\# Laboratoire d'Aérologie, Centre de Recherches Atmosphériques, Campistrous, 65300 Lannemezan, France

"Electricité de France, Direction des Etudes et Recherches, 78401, Chatou, France

${ }^{+t}$ Service d'Aéronomie du CNRS, Universite Paris VI, 75230, Paris, France

\#\# Laboratoire de Météorologie Physique, Universite Blaise Pascal, 63170, Aubière, France

(C) 1990 American Meteorological Society
}

boratoire des Sondages Electromagnétiques de l'Environnement Terrestre (LSEET), Centre de Recherches en Physique de I'Environnement (CRPE), Observatoire de Physique du Globe de Clermont (OPGC), Centre de Recherches Atmosphériques (CRA), the University of Balearic Islands (UIB), the University of Valladolid (UV), and the Deutsche Forschungsanstalt fur Luft und Raumfahrt (DLR). Funding is provided by DMN/EERM, INM, DLR, Institut National des Sciences de I'Univers (INSU/PAMOS), Centre National $d^{\prime}$ 'Etudes Spatiales (CNES), EDF/DER, and Région Midi-Pyrénées.

The purpose of the program is to establish a database for several detailed studies of the dynamic influence of a large and fairly simple mountain range, like the Pyrénées mountains, over the atmosphere.

The Pyrénées stand at the border between France and Spain (see figure 1). It consists of a massive barrier extending east-west over a length of nearly 400 $\mathrm{km}$ from the Atlantic Ocean to the Mediterranean, with a width varying from 30 to $70 \mathrm{~km}$, and a maximum height of about $3000 \mathrm{~m}$ in the central part. The highest point is the Peak Aneto (3404 m).

\section{Scientific issues for PYREX}

The motivations to undertake such an experiment can be classified in several categories. On the large scale, it is felt that an experimental assessment of the effect of orographic gravity waves on the mean flow will be needed in the near future. On the regional scale, several weather-producing types of flow require a better understanding. On the mesoscale, numerical modeling is currently experiencing rapid development, but still requires adequate testing against data in regions of marked orography.

\section{a. Large-scale aspects}

It is recognized that the main source of improvements for the general circulation models (GCM) in the past 10 years has been the introduction of very simple parameterizations of the subgrid-scale topography, such as the so-called "envelope orography," or the 
effect of mountain wave drag (Boer et al. 1984; Palmer et al. 1986). Most of these parameterizations have been based on two-dimensional (2-D) concepts. They have not been verified against observations, but rather "tuned" in order to improve the climatology of the GCM in which they were introduced (Geleyn and Rochas 1987). Although it is likely that these parameterizations partly remedy some weakness of the host model unrelated to subgrid-scale orography, their inadequacies strongly hint that further investigation is needed on the effect of mesoscale mountains on the large-scale flow. In addition, a second generation of these parameterizations, including three-dimensional (3-D) effects, is currently under way (Royer and Clary 1987; Miller and Palmer 1987). These future formulations will have more degrees of freedom and will require data for calibration. Meanwhile, the resolution of the GCM is constantly increasing and some of the concepts used in earlier versions may have to be adapted for smaller scales. Thus, it is necessary to acquire a database which could be used as a reference to test future parameterizations. An analogy may be found with the GARP Atlantic Trade-wind Experiment (GATE) experiment, which has provided high quality observations for testing convection parameterizations. However, the experimental problem here is more difficult since we are interested in the momentum budget, which includes pressure terms that are difficult to measure.

The Alpine Experiment (ALPEX) program (WMO 1986), which took place in 1982 over the Alps, brought considerable attention to the question of the influence of orography on the atmosphere. The wealth of collected data has in turn inspired new theoretical research in areas such as the blocking effect, lee cyclogenesis, mountain-pressure drag, frontal deformation, severe downslope wind, etc. Although the overall amount of high-quality data collected has been tremendous, a need still exists. For example, documenting the structure of the orographic boundary layer or analyzing in more detail the dynamic effects of the mesoscale mountain on the large-scale flow and the formation of local winds are areas requiring further study. Clearly, we need more emphasis on the experimental determination of the different contributions to the energy and momentum budget over the mountainous areas.

\section{b. Regional-scale aspects}

The regional perturbations induced by the orography on the mass, wind, temperature, and humidity fields, combined with marine effects, produce significant weather phenomena of great practical importance in the Pyrenean region. These alone would justify an experiment like PYREX. Some of these phenomena are regional winds, Catalonian and Balearic sea cyclogeneses, and convective storms.

It is well known that the Pyrenean range, together with the nearby Iberic range in Spain and Massif Central in France, induces typical regional wind systems. Those are the autan (a southeasterly wind occuring in France between Carcassonne and Toulouse), the tramontane (a northwesterly wind occurring at the easternmost part of the range, with a peak intensity near Perpignan, France), and the cierzo (a northwesterly wind occurring in Spain, in the central Ebro Valley, south of the Pyrenean range). It is suspected that those winds may be explained in part by the internal hydraulic approach, i.e., that the precise knowledge of the position and strength of an inversion layer at the top of the atmospheric boundary layer $(\mathrm{ABL})$ is of utmost importance to understanding their dynamics. Although the special observations made during ALPEX provided partial descriptions of the $A B L$ in points affected by local winds - as the cierzo (Riosalido et al. 1986) — their precise extent and quantitative characteristics are not well known.

Some of these winds are quite frequent and strong, most notably the tramontane, which is usually associated with the mistral, and is the main marine meteorological problem in the western Mediterranean.

In addition, foehn-type downslope winds occur occasionally on the foothills, leading to localized windstorms (Viers 1960), although these phenomena are less frequent and intense than the better-known Bora or Chinook. The Foehn effect has a marked impact on the regional climate, leading to higher mean temperatures and longer insolation (Viers 1987).

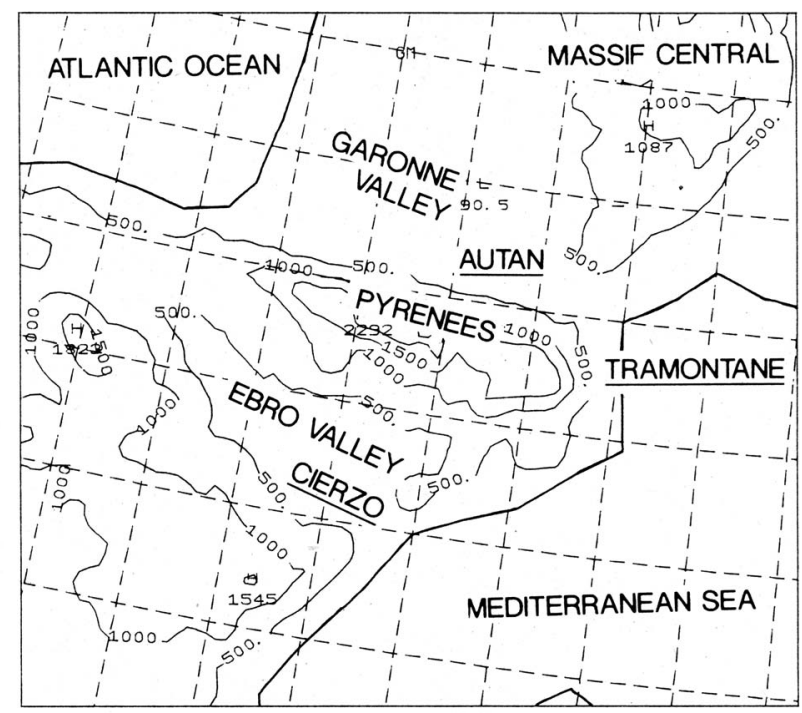

FIG. 1. The domain of interest for PYREX, with the major geographical elements. 
The high frequency of mesoscale low centers south or southeast of the Pyrénées is a relevant characteristic of the pressure distribution in the Iberia-Mediterranean region (Genovés and Jansà 1989), and is probably related to topographic influences. Occasionally, these lows seem to develop into a true cyclogenesis, sometimes explosive and intense, producing strong wind and precipitation events (e.g., Ramis and Ballester 1984); at other times these lows travel towards the Gulf of Genoa and enhance Alpine cyclogenesis events (Jansà et al. 1985).

Convective storms are driven by upslope and/or orographically deflected winds on both sides of the Pyrénées, sometimes resulting in damaging floods. As an example, on 6-8 November 1983, heavy rain (up to $300 \mathrm{~mm}$ ) in the Pyrénées produced floods in the southern slopes of the mountain range. Recently, on 3 October 1988, a flash flood caused by a convective cluster, that remained stationary for 6 hours, brought substantial damage to the city of Nîmes, France. It is suspected that the origin of this phenomenon was a low-level convergence line caused by the Pyrénées, more than $200 \mathrm{~km}$ upwind. Catalonia also experienced significant damage triggered by this event and by a chain of other convective events during this period. Until now, understanding of these phenomena has been inhibited by poor observational support.

\section{c. Mesoscale aspects}

On the mesoscale, the major motivation is provided by the rapid development of numerical models, which require careful validation. A database describing the preconditions of phenomena like those above would be already valuable for meso- $\alpha(30 \mathrm{~km}-50 \mathrm{~km}$ resolution) numerical experimentation and validation of parameterizations. Such work would go a long way toward improving the forecast. But the increasing power of computers makes it possible to foresee the development of operational-forecast models having a capacity to resolve meso- $\beta$-scale motions on a horizontal mesh of about $10 \mathrm{~km}$. Such forecast models are already being run on a research mode. Continued development of meso- $\beta$ modeling capability will allow for important progress in the numerical forecasting of weather elements on smaller scales.

However, it is known that forecast results at these scales are strongly dependent on several factors which are still poorly understood. Those are

- The vertical resolution of the model, especially in terms of minimum necessary resolution in the PLB and near the tropopause;

- The definition of the surface geopotential at each grid point of the model;
- The definition of the dynamic and thermal roughness parameters at the scale of a model grid box (especially difficult over steep orography);

- The correct representation of the cloud formation and dissipation;

- The correct representation of the vertical and horizontal diffusion terms, which may be strongly enhanced by mountain-wave-induced turbulence.

Currently, there is much theoretical work being done on these different problems, resulting in conflicting proposals. For instance, either the "envelope orography," (Jarraud et al. 1987) or the "silhouette orography" (Messinger and Janjic 1987) have been proposed. Several practical methods to determine regional dynamic roughness have been described (Smith and Carson 1977; Mason 1987, 1988). The effect of latent heat release on the amplitude of mountain wave has been analyzed (Durran and Klemp 1982; Nickerson et al. 1986). Finally, some equations to account for turbulence kinetic energy have been introduced in mesoscale models (Richard et al. 1989; Buty 1988; Bougeault and Lacarrère 1989). All these results demand further experimental verification.

\section{A modeling strategy}

There is obviously a close link between the largerand smaller-scale objectives. The development of efficient parameterization schemes accounting for the effect of subgrid-scale orography in GCM depends on a better understanding of the mechanisms that occur on small scales. Recent theoretical progress on certain topics, such as blocking and deviation of atmospheric flow by mountains, have relied upon numerical models (e.g., Pierrehumbert and Wyman 1985). It appears therefore, that further progress in this direction will require better validation of those models. Thus, the experimental strategy of the PYREX project is focused on obtaining measurements over specific areas of the mountain range to allow for the precise validation of several mesoscale models. Then, validated model outputs will give indirect access to the other unknowns of the problem, namely the different terms of the momentum budget in the vicinity of the mountain range, which would be impractical to measure directly.

\section{a. Theoretical concepts}

For illustration purposes let us consider the equation for the zonal wind velocity

$$
\frac{\partial \rho u}{\partial t}=-\frac{\partial \rho u^{2}}{\partial x}-\frac{\partial \rho u v}{\partial y}-\frac{\partial \rho u w}{\partial z}-\frac{\partial p}{\partial x}+\rho f v
$$


We want to average this equation on a 3-D box in order to retrieve the significant contributions for larger-scale models. Let us define $(\sim)=\int_{h(x, y)}^{z_{T}} d z$ as a vertical averaging operator between the ground at altitude $h(x, y)$ and an arbitrary level $Z_{T}$, and $\overline{(\quad)}=\int_{x y} d x d y$ as an horizontal averaging operator on the surface of the box. The mean momentum budget will read

$$
\frac{\overline{\partial \widetilde{\rho u^{2}}}}{\partial t}=-\frac{\overline{\partial \widetilde{\rho u^{2}}}}{\partial x}-\frac{\overline{\partial \widetilde{\rho u v}}}{\partial y}-\overline{\rho u w\left(Z_{T}\right)}
$$

(a)

(b)

$$
+\overline{\rho u w(h)}-\frac{\partial \tilde{p}}{\partial x}+\overline{\rho f \tilde{v}}-\overline{p(h) \frac{\partial h}{\partial x}} \text {. }
$$

$$
\text { (c) } \quad(d) \quad \text { (e) } \quad \text { (f) }
$$

Equation 2 offers an opportunity to discuss the different quantities that need to be determined, either directly (measurements) or indirectly (mesoscale models). Those are (a) the lateral advection of momentum at the boundaries; (b) the flux of momentum at the top (which classically is decomposed into a wave part and a turbulent part); (c) the flux at the lower boundary (which is, in principle, a turbulent flux); (d) the mean pressure gradient; (e) the Coriolis force; and ( $f$ ) the pressure drag at the ground.

In order to evaluate these terms, it is necessary to measure

- The 3-D structure of the wind and the temperature around the range (terms [a], [d], and [e]). This is clearly not possible everywhere, and the location of the measurements should be considered very carefully. Special attention should be given to the lowlevel regional winds resulting from the contouring of the range, and enter in the determination of (a);

- The wave and turbulent fluxes of momentum at several heights, and along carefully chosen axis. Their sensitivity to the presence of clouds, and to the liquid water content of these clouds should be considered;

- The surface pressure, with a sufficient accuracy to compute the integral (f); and

- The surface turbulent momentum flux (c), which calls for estimates of the regional roughness.

Since it is impossible to take such measurements everywhere in space in a box of say, $600 \mathrm{~km} \times 600$ $\mathrm{km}$ around the mountain range (see Figure 1), it will be necessary to rely on the results of the mesoscale models to obtain an indirect estimate of the different terms. It is proposed to organize the measurements in order to validate the most sensitive aspects of the model dynamics.

This strategy is guided by the conceptual view of the flow past a 3-D meso-beta-scale mountain sche- matically depicted in figure 2 . The salient features of the flow patterns are

1) The formation of a blocked zone upstream of the mountain. In this region, the wind velocity is weak. The effective vertical profile of the mountain as seen by the large-scale flow will depend on the extension of this blocking zone, and therefore, the amount of the energy radiated upward by gravity waves.

2) Upstream of the blocking zone, the low-level flow splits into two branches diverted laterally around the mountain. The horizontal position of the dividing streamline varies with the large-scale flow. Mesoscale models also show that, for a given large-scale flow, the horizontal position of the dividing streamline varies with the altitude and may turn around the mountain to a significant extent.

3) On the lateral edges of the mountain, the deviation results in flow with strong curvature in the lower levels and less perturbed flow aloft. There is, therefore, a significant wind shear through a deep layer, with a complex 3-D structure. The associated amount of turbulence and the vertical transfer of momentum are not well-known.

4) Depending on the vertical stability profile, the low-level flow may be accelerated to form a welldefined regional wind, either upstream or downstream of the obstacle. In this case, there is a strong decoupling of the $A B L$ from the free atmosphere. The $A B L$ is usually capped by a well-defined inversion, and the exchange of momentum by turbulence through this inversion becomes of central interest for the behavior of both the ABL and upper-level flow.

5) The flow is accelerated above the main ridge. A dynamic boundary layer is formed, with strong turbulence in the lower levels. The maximum wind speed will depend on the roughness, which is difficult to define. The vertical extension of this turbulent boundary layer above the main ridge is of interest but is poorly known.

6) Gravity waves are generated by the central part of the mountain. They transfer momentum vertically and may break, resulting in production of turbulence and strong downslope wind formation. One expects to observe the formation of a turbulent wake and a significant deformation of the tropopause above the main ridge.

7) Finally, it is an observed fact that a zone of weak, low-level wind is often present immediately downstream of the main ridge, as a result of a sheltering effect.

These features may or may not appear simultaneously. However, all of them should participate ac- 
tively in the regional momentum budget and it appears necessary to organize the experimental strategy in order to document points 1 to 7 . This rationale was taken into account in the definition of a number of specific experimental objectives, as explained in section 4 .

b. The models for PYREX

It is foreseen that numerical simulations using PYREX data will be made with five different mesoscale models:

1) The Spanish INM LAM, derived from the European Centre for Medium-Range Forecasts (ECMWF)
(LAM) (Hortal et al. 1986). This model is planned to be improved during 1990, with higher resolution and a better-tuned physical parameterization package;

2) the French Weather Service PERIDOT model. This is an operational model, with a complete sequential data-assimilation suite (Imbard et al. 1987). A research version of this model allows for meso- $\beta$ scale simulations;

3) the SALSA model of Laboratoire de Météorologie Physique (Nickerson et al. 1986); and

4) the HERMES and MERCURE models of Electricité de France/DER. These models are being developed by the French Electricity Agency to provide

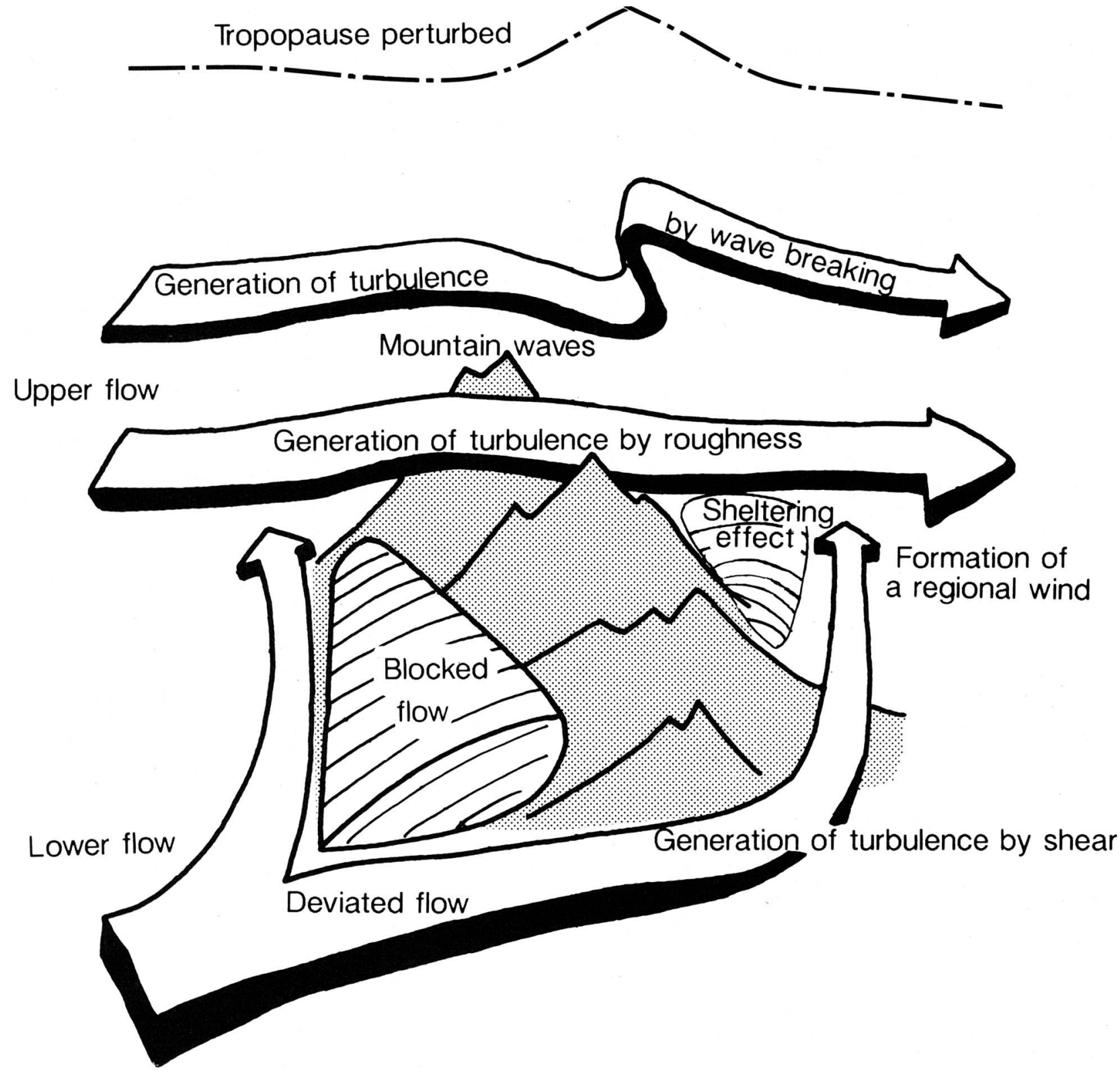

FIG. 2. A schematic of the flow around and over the Pyrénées (see subhead a in section 3). 
short-term environmental protection (Buty 1988).

Some characteristics of these models are given in Table 1. All of the models have 2-D versions that allow for inexpensive systematic intercomparison on selected test cases before the experiment. This program will also allow for comparison between hydrostatic and nonhydrostatic model results. Before the experiment the models are used to plan optimum flight tracks and to assess the feasibility of the balloon experiment (Stein 1989). As an example, Figure 3 shows the trajectories simulated by the PERIDOT model for several launching sites and two different flight levels. The strong curvature of the low-level flow around the eastern edge of the mountain and the resulting vertical shear are some of the elements which are of interest for turbulence generation, but deserve serious experimental verification. After completion of the field phase the scientific objectives will be divided into the two following topics.

\section{c. Validation of the models}

The mesoscale objective analyses of the French Weather Service, including the additional radio soundings, will be used to initialize the 3-D simulations on the domain shown in Figure 1 and provide boundary conditions during the course of the integrations. The model results will be assessed by use of the supplemental observations during Intensive Observation Periods (IOPs), with particular attention given to the pressure drag across the mountain and the structure of the main wave in a $2-D$ vertical cross section. The reconstituting of the variables measured by the aircraft in the regional $A B L$, using interpolation of model output along the flight tracks, will be another powerful way to check the quality of the simulations. The trajectories of the constant-level balloons will be computed from the model output, and compared to the observed ones. The specification of the free parameters of the models will be improved by trial and error, until a satisfactory agree- ment with the observations can be found. Particular attention will be given to the surface-roughness parameters, the horizontal diffusion coefficients, and the surface geopotential in this adjustment process. Several parameters used in the cloud- and rain-water computations will also need calibration (i.e., the autoconversion efficience coefficient). The validation phase will end when a reasonable behavior of the models can be obtained for several IOPs.

\section{d. The models as numerical laboratories}

It is believed that once validated in the way described above, the mesoscale-model results will provide the best possible picture of the atmosphere during the IOPs. They will then be used to improve our understanding of the physical processes occurring in the vicinity of a major mountain range. For instance, using an analysis of streamline on isentropes, the model domain will be divided into several parts corresponding to blocked flow, laterally diverted flow, or verti-

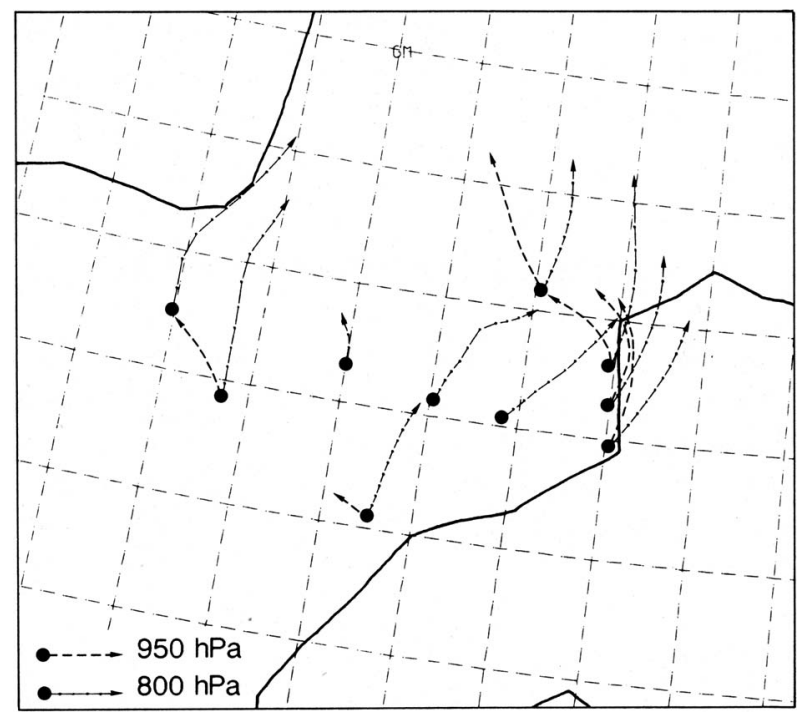

FIG. 3. An example of trajectories computed from the French Weather Service PERIDOT model outputs (from Stein 1989).

TABLE 1. The models for PYREX

\begin{tabular}{|c|c|c|c|c|c|c|}
\hline Model & Institute & Equations & $\begin{array}{l}\text { Horizontal } \\
\text { Resolution }\end{array}$ & $\begin{array}{l}\text { Vertical } \\
\text { Resolution }\end{array}$ & Physics & $\begin{array}{c}\text { Data } \\
\text { Assimilation }\end{array}$ \\
\hline PERIDOT & CNRM & Hydrostatic & $\Delta \mathrm{x}=10-35 \mathrm{~km}$ & $\begin{array}{l}\Delta z=100 \mathrm{~m} \text { in } \mathrm{PBL} \\
1 \mathrm{~km} \text { aloft }\end{array}$ & Complete physics & Yes \\
\hline SALSA & LMP & Hydrostatic & $\Delta \mathrm{x}=10 \mathrm{~km}$ & $\begin{array}{c}\Delta z=100 \mathrm{~m} \text { in } \mathrm{PBL} \\
1 \mathrm{~km} \text { aloft }\end{array}$ & $\begin{array}{l}\text { Complete physics } \\
\text { except deep } \\
\text { convection }\end{array}$ & No \\
\hline HERMES & EDF/DER & Hydrostatic & $\Delta \mathrm{x}=10 \mathrm{~km}$ & $\begin{array}{c}\Delta z=20 \mathrm{~m} \text { in } \mathrm{PBL} \\
1 \mathrm{~km} \text { aloft }\end{array}$ & $\begin{array}{l}\text { As above with different } \\
\text { parameterization }\end{array}$ & No \\
\hline MERCURE & EDF/DER & Non-hydrostatic & $\Delta \mathrm{x}=500 \mathrm{~m}-2 \mathrm{~km}$ & $\begin{array}{l}\Delta z=10 \mathrm{~m} \text { in PBL } \\
100-500 \mathrm{~m} \text { aloft }\end{array}$ & Dry physics & No \\
\hline INM LAM & INM & Hydrostatic & $\Delta \mathrm{x}=35-75 \mathrm{~km}$ & $\begin{array}{l}\Delta \mathrm{z}=100 \mathrm{~m} \text { in } \mathrm{PBL} \\
1 \mathrm{~km} \text { aloft }\end{array}$ & Complete physics & Yes \\
\hline
\end{tabular}


cally deflected flow. The momentum budgets of these different stream tubes will be computed. The extension of these regions will be compared to theoretical predictions from the Froude number. Another potential focus of research will be on computing largescale values of the parameters by spatial averaging of the model output and verifying the assumptions underlying the drag-parameterization theories.

Sensitivity studies made by changing some aspects of the reference simulations will also offer an interesting investigational approach. Changing part of the model physics will provide insight into the interplay of the different physical mechanisms. Changing the horizontal resolution of the models will allow for an assessment of the respective roles of roughness and form-drag in the mountain-induced resistance to the mean flow. This will allow the derivation of some rules for specifying roughness appropriate for the model grid size. Finally, some simulations may be run with an idealized topography instead of the real one, in order to investigate the fundamental dynamics of the interaction between the flow and the obstacle. This may allow for the exporting of the PYREX results to other parts of the world.

\section{Experimental approach to PYREX}

Given the general strategy explained above, the experimental approach will concentrate on four specific objectives, to be carried out either simultaneously or alternatively, depending on the weather conditions and aircraft availability. Those are described in the following sections.

\section{a. The regional 3-D distribution of the meteorological elements}

An enhanced 3-D observational effort is needed at the regional scale, both for phenomenological studies and as an improved input for high-resolution numerical models. This is particularly true for the regional $A B L$, but also for the tropospheric flow.

As explained above, it is of prime interest to document geometrical aspects of the regional $A B L$, such as the horizontal extent, vertical depth of wind systems, and the height of the inversion. Particular care will be given to the transition zone from the windy region to the nonwindy one, especially sharp in the western edge of the Tramontane (Jansà 1987). It will be necessary to get a clear picture, at any time during the experiment, of how the flow partitions itself into blocked air masses, and air masses which are laterally or vertically diverted.

The best tools for this kind of investigation are, of course, instrumented aircraft. It is planned to dedicate one or two of the PYREX aircraft to this objective, depending on the meteorological situation. The main task will be to document the 3-D mean structure of the $A B L$ around the eastern part of the range (flight plans 1 and 2 in figure 4). However, the 3-D mean structure of the upper airflow will be also documented by a box-type flight pattern (flight plan 3 in Figure 4). These measurements will be completed by a large number of surface-based measurements. There will be 11 sounding sites, organized in arrays at both the meso- $\beta$ and meso- $\alpha$ scales. Several surface networks of automated weather stations will run during the experiment. Several acoustic sounders (Sodar) will also be available and will continuously record at those sites where regional winds are expected. However, the most original aspect of the experimental setup will be the use of constant-level balloons. These carriers will flow with the airmass at three different altitudes. They will be released from one of two sites on the eastern edge of the mountain range, depending on the direction of the mean flow, and will be tracked by radar. Their trajectory will provide insight into the 3-D structure of the wind field in the deflection area. They will be equipped with sensors to measure pressure, temperature, and moisture.

\section{b. Momentum transfer and turbulence characteristics in the regional wind systems}

The vertical transfer of momentum by turbulence is presumed to be one of the key factors in understanding the quantitative behavior of the regional wind system and the area-mean momentum budget. This calls for a detailed experimental study of the turbulence associated with a boundary-layer wind, which experiences mesoscale forcing by the complex orography, the wind shear at the ground, and wind shear near the $A B L$ top. Of special interest are the turbulent momentum-flux profile; the effect of the entrainment at the top of the wind layer; the budgets of heat and turbulence kinetic energy (including horizontal advection terms, which are important); the characteristic scales of turbulence; and the spectra.

At present time, research aircraft equipped for turbulence measurements are the only appropriate means for such a detailed study. It is planned to use three of the PYREX aircraft for simultaneous missions dedicated to this objective. Two of them will take turbulence measurements, and the third will take only mean measurements in the mesoscale environment.

\section{The main vertical cross section}

A central objective of the PYREX program will be the 
documentation of the tropospheric momentum budget over the main mountain ridge. Recalling the discussion of equation 2, previous results on the term (b) have been reviewed by Hoinka (1987), who found few well-documented cases, because meteorological situations where (b) is important are not frequent. Thus, there is particular difficulty in the planning of an aircraft experiment and the necessity for continuous measurements for a long period in order to catch interesting cases. However, there is an excellent correlation between strong values of the momentum flux in the troposphere and strong winds or pressure drag at the surface. This calls for coordination between aircraft, continuously operating profilers, and a surface network of microbarographs. Thus, aircraft operations could be initiated when events are most likely. Hoinka (1987) also noted that in previous works the Coriolis term (c) has been neglected. However, Smith (1979) has shown that this term may account for $20 \%$ of the flux. Finally, several examples of calculation of the pressure drag (f) are available (e.g., Carissimo et al. 1988). In a review of these results, Davies (1987) concludes that this term is now within the reach of carefully designed microbarograph systems.

Given the simple geometry of the Pyrenean range, it is proposed that a large number of measurements be concentrated along a vertical cross section perpendicular to the range in its central part (figure 5).

Those are

- a network of ground stations measuring the wind, temperature, and pressure with sufficient accuracy to compute the drag;

- several acoustic sounders measuring the wind in the $A B L$ up to about $600 \mathrm{~m}$;

- several profilers providing continuous measurements of the horizontal and vertical wind up to the tropopause, with a vertical resolution of a few

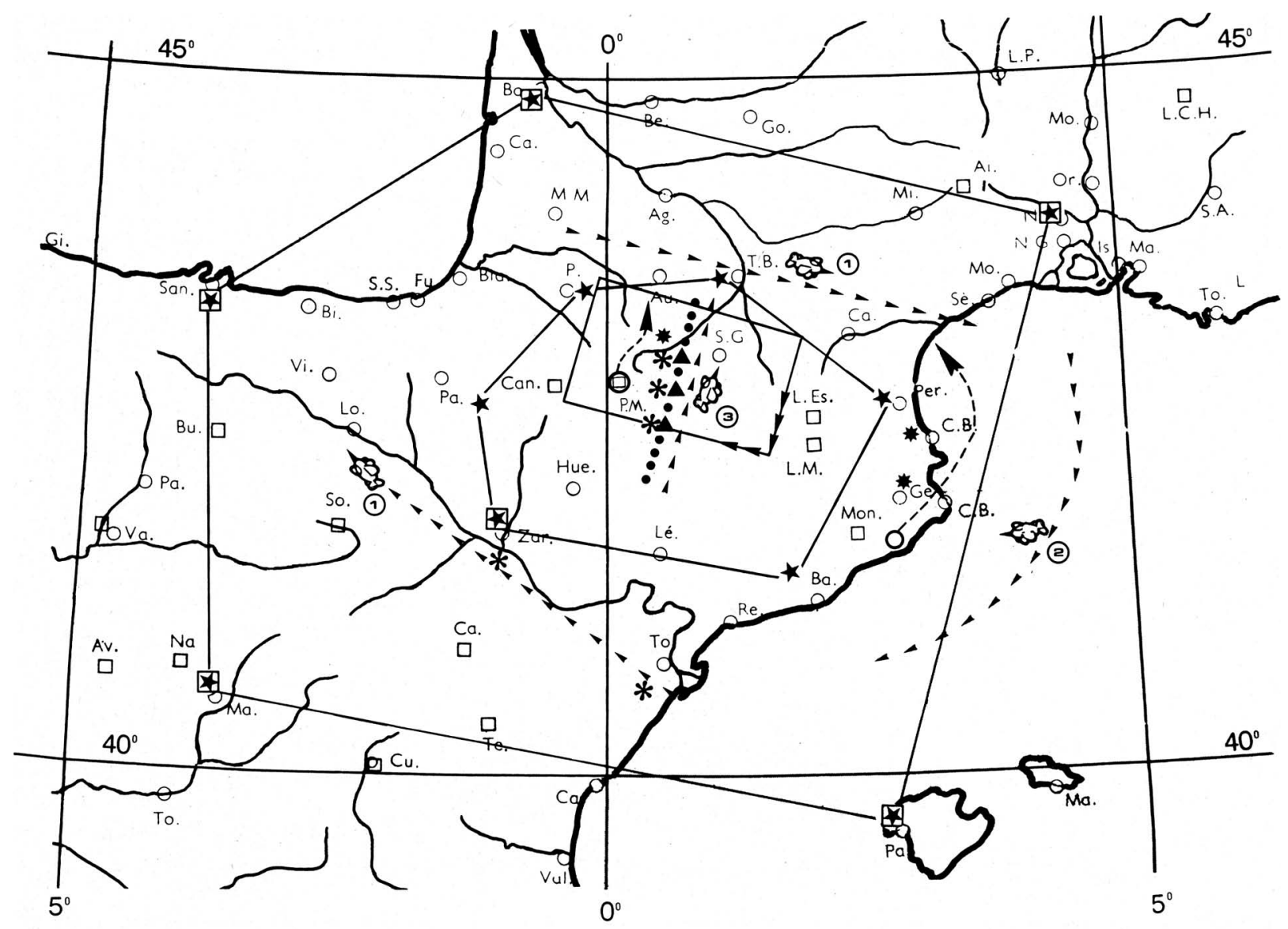

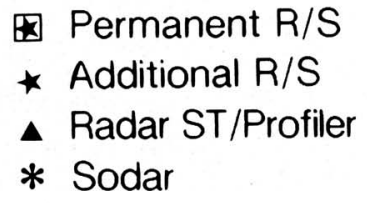

Permanent R/S

* Additional R/S

* Sodar

FIG. 4. The general experimental design and the location of the main flight areas. 
hundred meters;

- instrumented aircraft, flying simultaneously at different altitudes and taking measurements of mean and turbulence parameters, microphysics, and radiation fluxes;

- the airborne backscatter lidar LEANDRE I, capable of zenith and nadir viewing, which will provide a documentation of the ABL structure, wave activity, cloud formation, and the tropopause height modification, associated with the presence of the Pyrenean barrier;

- constant-level balloons launched from an elevated site on the mountain range and tracked by radar from the plain nearby. These balloons will fly in the wake of the mountain and provide information on the lee waves and turbulence near $3000 \mathrm{~m}$.

This ensemble of measurements should provide a fairly complete picture of the atmosphere in the 2-D cross section. As opposed to previous experiments, where only the surface drag, or the dynamic and turbulence parameters at some height were measured, the PYREX project will provide simultaneous mea- surements of pressure drag, $A B L$ structure, $A B L$ top, tropopause location, clear-air turbulence layers, the wave structure, and the geometry and liquid-water content of the clouds embedded in the wave systems. Special attention will be given to the influence of cloud-induced stability reduction on the wave structure.

\section{d. The regional thermal- and dynamic-roughness parameters}

To close the momentum budget of the atmosphere, it is necessary to have a clear picture of the momentum fluxes at the lower boundary. This calls for estimates of regional-roughness parameters. These estimates are particularly difficult in mountainous region, because of the very complex ABL. It is proposed that those estimates be a tentative objective and, as such, will act as an opportunity to develop new methodologies.

Direct estimates of the roughness may be obtained by a careful treatment of the available soundings or sodar-derived wind profiles in the lower levels. It is also proposed that some of the aircraft missions be

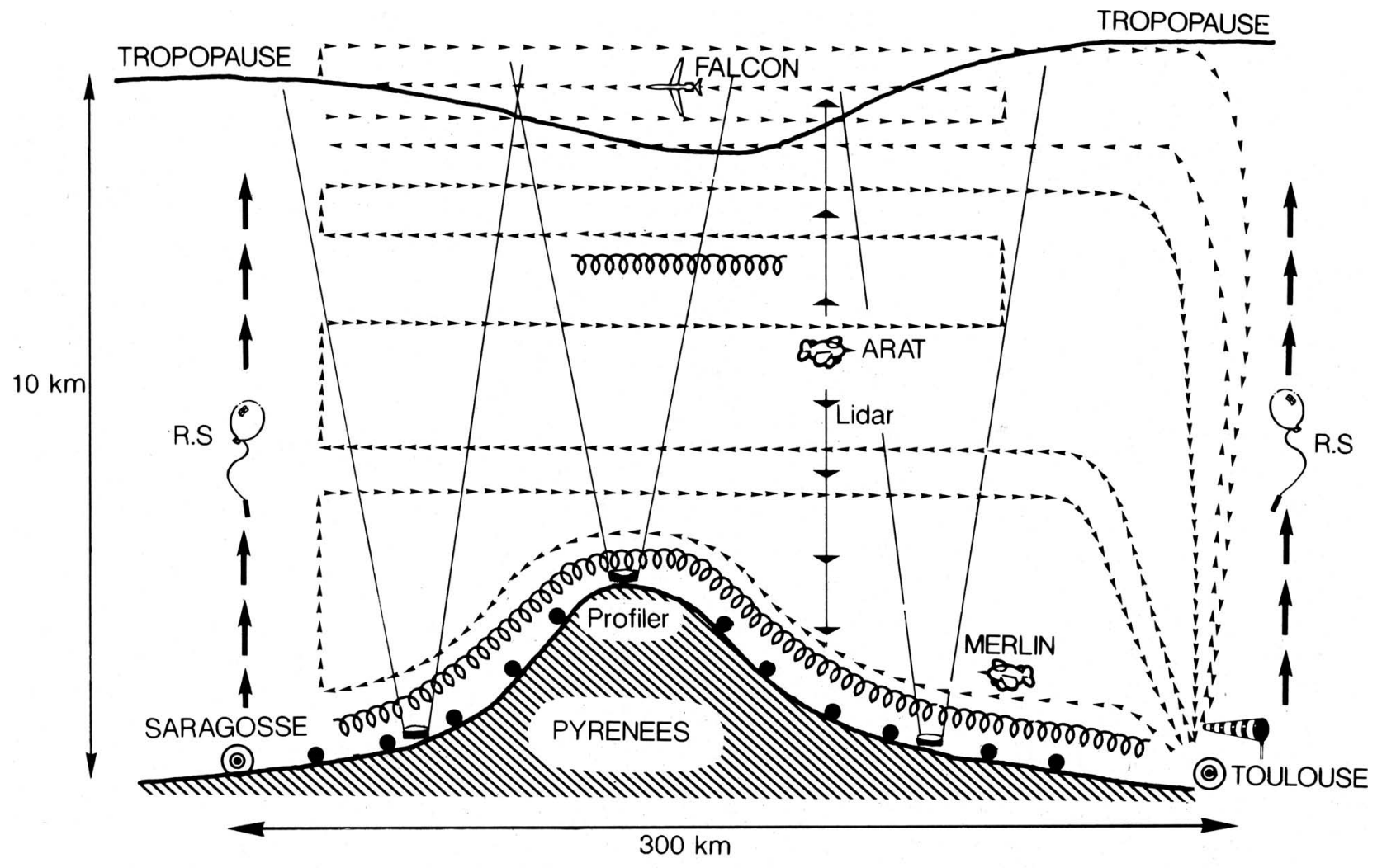

\footnotetext{
- Ground network of microbarographs

wr Turbulence

b Profiler + Sodar
}

FIG. 5. Experimental design for the main vertical cross section. 
dedicated to this problem. Flying at low altitudes, the aircraft may take measurements of the mean and turbulent parameters that will help derive a representative value of the regional roughness. However, it is also foreseen that indirect estimates of the roughness may be obtained by tuning the model parameters to obtain the best possible results at low levels. This could be done in a very elegant way by the use of the adjoint technique (Talagrand and Courtier 1987) currently under development on a 2-D $(x, z)$ research model at CNRM. Both approaches will provide a valuable set of results. This part of the project could also offer an opportunity to establish collaboration with scientists working to determine the roughness using remote-sensing techniques.

\section{The planning of the experiment}

The experiment was initially proposed in September 1987. During the year 1988, a project group was created among interested scientists of several institutions from Spain, France, and Germany.

The project group decided to conduct the field phase of the PYREX project in October and November 1990. This period of the year was chosen because it is one of the most favorable to obtain a large number of interesting situations (i.e., a large rate of occurrence of flows transverse to the main mountain ridge). Additionally, it is known that this period of the year is favorable for the occurrence of low-level winds. Because the maintenance of the surface network for the defined cross section will require operations at high-altitude conditions, it was decided to terminate the experiment at the end of November, to avoid logistic problems created by winter conditions in the mountains.

It was further decided to concentrate aircraft and balloon measurements on six IOPs of two- to threeday durations corresponding to interesting meteorological conditions, which will be determined in real time from an operation center in Toulouse. The major objective will be to catch situations of wave activity over the Pyrénées and/or strong, low-level winds in the ABL. An effort will be made to collect a dataset representing various conditions, corresponding to a variety of high-level wind directions. Because this pattern is reasonably predictable by operational NWP systems, the starting of an IOP will be decided about two days in advance.

\section{a. Upper-air soundings}

There will be 11 upper-air soundings for the PYREX database. These soundings will be transmitted in real time on the Global Transmission System (GTS), as possible. The soundings will be organized in two arrays, corresponding to the meso- $\alpha$ or the meso- $\beta$ scale. They will be either permanent soundings of the operational network $(\mathrm{P})$ or mobile soundings activated for the experiment (S). The different soundings are located as shown in Figure 4. Following are their locations.

Meso- $\alpha$ scale: Bordeaux (P), Nîmes (P), Palma (P), Madrid (P), and Santander ( $\mathrm{P})$.

Meso- $\beta$ scale: Toulouse (S), Saragosse (P), Pau (S), Perpignan (S), Barcelona (S), and Pampeluna (S).

During non-IOPs only the regular soundings of the operational network will be run. During the IOPs, all the soundings will be made every 6 hours. These soundings will be run to at least the height of the tropopause.

\section{b. Surface networks}

During the experiment, several operational networks of automatic weather stations in southwestern France and Spain will operate as usual (before the experiment, the INM plans to upgrade several of its stations with pressure sensors). These will provide surface data with sufficient density, except on the mountain itself and in the northeastern part of the domain of interest. This will require the installation of two specially operated networks: 1) Electricité de France will operate five stations along an axis Toulouse-Narbonne in order to gather data for objective a in Section 4 and 2) the Mobile Surface Network of CNRM will be devoted to objective $\mathrm{c}$ in the same section. Fifteen stations will be installed along the main transect and will include microbarographs to compute the drag (the altitude of these stations has been determined with an accuracy better than $10 \mathrm{~cm}$ by the Institut Geographique National).

All these networks will operate continuously during the experiment. The computation of the pressure drag will run in real time, in order to allow for an optimal planning of aircraft operations. This is made possible by the concentration of the network data through the geostationary satellite METEOSAT.

\section{Acoustic sounders}

Several sodar systems will be used to document the ABL structure. They will be located both along the main transect and at places where regional winds are expected. These devices will be operated by EDF, CRPE, UV, and INM (see figure 4).

\section{d. Wind profilers}

Three VHF wind profilers of the French DMN/INSU research network (Petitdidier et al. 1986) will be available at the time of the experiment. These devices 
will be located along the main transect, near Ainsa, Spain, and Saint-Lary and Lannemezan, France. They will be operated jointly by OPGC, CNRM, LSEET, CRPE, and CRA.

They will provide continuous measurements during the experiment, with two possible vertical resolutions: $375 \mathrm{~m}$ (up to $12 \mathrm{~km}$ ) or $2250 \mathrm{~m}$ (up to 18 $\mathrm{km}$ ). These two modes will be used alternatively. In addition, a UHF wind profiler will be operated in Lannemezan by CRPE and CRA, and will provide higher-resolution wind measurements up to $6 \mathrm{~km}$ in the wake of the mountain range. The measurements will be made available with a time resolution of 1 hour for the mean horizontal and vertical wind profilers, and a few minutes for individual components. The data of the four profilers will be available in nearreal time and will help in planning the aircraft operations.

\section{e. Instrumented aircraft}

The research aircraft will be based in Toulouse, France. At the present time it is planned to use four research aircraft.

1) The Fokker 27 (ARAT), belonging to a group of French institutes (CNES, INSU, DMN, and IGN), allows for measurements of mean and turbulent components of the wind, temperature and moisture, radiation, and microphysical properties (INSU 1987). It carries the lidar LEANDRE I, which will determine the spatial distribution of the atmospheric particles used as dynamic tracer. In the nadir-viewing mode, measurements can be performed with crosstrack scanning to minimize small-scale horizontal inhomogeneity. This aircraft will be able to fly about 15 missions of 4 hours duration for the whole experiment.

2) The Merlin IV of DMN/EERM (CAM Bulletin, no. 3, 1987) will have the same capacities as the Fokker 27, except for the airborne lidar. It will be used simultaneously with the Fokker 27, to cover a different range of altitudes. Provision is made for 15 missions of 4 hours duration for this aircraft.

3) The Piper Aztec of DMN/EERM (CAM Bulletin, no. 2,1985 ) will have the capacity to measure mean parameters only. This aircraft will be used to document the mean characteristics of the regional $A B L$ and the 3-D distribution of the weather elements. Provision is made for $40 \mathrm{~h}$ of scientific missions.

4) The Falcon of the DLR will focus its effort on the description of the higher levels of the main vertical cross section. It will take measurements of mean and turbulent parameters. Thus, the plan is to have three aircraft with turbulence capacity flying simultaneously at different altitudes when wave activity is present (see figure 5).
A possibility exists to use one more instrumented, high-speed aircraft to document the 3-D structure of the flow at high altitude around the mountain range during the IOPs.

Also, the possibility to increase the frequency of AIREP-type reports by commercial aircraft during the experiment is investigated. These measurements are usually taken at a high altitude, near the tropopause, where few measurements will be available. They will therefore provide a complementary dataset of high interest.

\section{f. Constant-level balloons}

Constant-level balloons (Benech et al. 1987) will be operated by the CNES and equipped by L.A. They will be launched from two different sites on the northern and southern sides of the mountain range, in the region of strong wind deflection (see figure 4). They will be tracked by two radars, allowing for a trajectory of about $100 \mathrm{~km}$ and will take measurements of pressure, temperature, and moisture. The wind field will be deduced from their trajectories. Three different flight levels will be used (700, 1500, and 3000 $\mathrm{m})$. Balloons will be launched only during the IOPs.

An additional site for balloon launching will be located on Pic du Midi (2900 m) close to the main transect. Balloons at flight level $3000 \mathrm{~m}$ will be launched from this site simultaneously with aircraft operations on the main transect. They will be tracked by a radar located in Lannemezan. Their trajectory will provide information in the turbulent wake of the main range and on lee waves downstream of it.

\section{g. Meteorological analyses}

Operational small-scale analyses of the French Weather Service (Durand et al. 1989) have been very useful in past experiments to initialize research models. It is foreseen that all the information necessary to perform these analyses (conventional and satellite data), as well as the analyses themselves, will be archived during the IOPs as part of the PYREX database. At the end of the field phase, a quick look Atlas will be produced from these products.

\section{h. Satellite and radar pictures}

All the products of METEOSAT and NOAA satellites, as well as the information from the French and Spanish radars, will be archived during the IOPs.

\section{Conclusion}

The PYREX project will provide an interesting opportunity to understand the dynamical influence of a 
large mountain on the meso- $\beta$-scale flow. Invited studies are welcome. Interested scientists should contact P. Bougeault CNRM, 42 avenue Coriolis, 31057 Toulouse Cedex France.

Acknowledgments. The PYREX project is made possible by the personal commitment of many colleagues of the different institutes. We would like to thank especially P. Bessemoulin, J. L. Brenguier, T. Phulpin, P. Pettre, V. Klaus, N. Raynal, J. Stein (CNRM), M. Andre (CAM), C. Villien (LIMMA), A. Druilhet, P. Durand (LA), D. Rouseau, C. LeFevre (DMN/ENM), P. Mascart, D. Ramond, G. Dubosclard (LAMP/OPGC), M. Crochet (LSEET), M. Petitdidier (CRPE), K. P. Hoinka, M. Reinhardt (DLR), P. Flamant (LMD), J. L. Casanova (UV), S. Alonso (UIB), M. Hortal, R. Diaz-Pabon, and M. Lambas Senas (INM).

We are also indebted to D. Guedalia (INSU/PAM), J. C. Andre, F. Delsol (EERM), and A. Ascaso Liria (INM) for their help and encouragements.

Finally, thanks are due to D. Lacarrere, who found her way through the numerous versions of this manuscript.

\section{References}

Benech, B., A. Druilhet, R. Cordesse, B. Dartigues-Longues, J. Fournet-Fayard, J. C. Mesnager, P. Durand and A. Malaterre. 1987. Un dispositif expérimental utilisant des ballons plafonnants pour l'étude de la couche limite atmosphérique. Adv. Space. Res. 7: 77-83.

Boer, G. J., N. A. McFarlane and R. Laprise. 1984. The climatology of the canadian climate center general circulation model as obtained from a five-year simulation. Atmosphere-ocean 22: 430-473.

Bougeault, P. and P. Lacarrère. 1989. Parameterization of orography-induced turbulence in a meso-beta scale model. Mon. Wea. Rev. 117: 1870-1888.

Buty, D. 1988. Paramétrisation de la turbulence atmosphérique dans un code méso météorologique tridimensionnel et non-hydrostatique. Thèse de Doctorat, Université Claude Bernard, Lyon 1.

CAM Bulletin, no. 2. 1985. The Piper-Aztec aircraft: summary of performances and instrumentation (Available from Centre d'Aviation Météorologique 91220 Brétigny-sur-Orge, France).

CAM Bulletin, no. 3. 1987. General description of the instrumented aircraft Merlin IV GMTO (available from Centre d'Aviation Métérologique, 91220 Brétigny-sur-Orge, France).

Carissimo, B., R. T. Pierrehumbert and H. L. Pham. 1988. An estimate of mountain drag during Alpex for comparison with numerical models. J. Atmos. Sci. 45: 1949-1960.

Davies, H. C. 1987. Observational studies and interpretation of the mountain pressure drag during Alpex. ECMWF, 113-136.

Durand, Y., P. Bougeault and M. C. Pierrard. 1989. Use of satellite data in the Péridot Mesoscale Assimilation system. Part I: The analysis model. To appear in Tellus.

Durran, D. R. and J. B. Klemp. 1982. The effects of moisture on trapped mountain lee waves. J. Atmos. Sci. 39: 2490-2506.

Geleyn, J. F. and G. Rochas. 1987. Influence de la paramétrisation des ondes de gravité orographiques sur les erreurs systématiques du modèle Emeraude. AMA 87: 129-137.

Genoves, A. and A. Jansà. 1989. Statistical approach to mesoscale non-alpine west mediterranean cyclogenesis. XIV General Assembly of the EGS, Barcelona, Special Issue of Annalas Geophysicae $\mathbf{1 7 2}$.
Hoinka, K. P. 1987. Observational studies of mountain generated momentum fluxes. ECMWF: 137-166

Hortal, M., A. Jansa and C. Gimeno. 1986. Spanish LAM behaviour in two cases of Mediterranean Cyclogenesis. Scientific results of the Alpine Experiment (ALPEX), WMO/TD 108: 195206.

Imbard, M., A. Craplet, P. Degardin, Y. Durand, A. Joly, N. Marie and J. F. Geleyn. 1987. Fine-mesh limited area forecasting with the French Operational PERIDOT System. Proceedings of the seminar: "The nature and prediction of extra tropical weather systems". ECMWF, 7-11 September 1987.

INSU. 1987. ARAT: the atmospheric research and teledetection aircraft. INSU/DT technical note (in French), available from INSU, 77, avenue Denfert Rochereau, 75014 Paris, France).

Jansà, A. 1987. Distribution of the Mistral: A satellite observation. Meteor. Atmos. Phys. 36: 201-214.

Jansà, A., S. Alonso, C. Ramis, M. A. Heredia and J. A. GarciaMoya. 1985. Non-alpine contributions to mediterranean cyclogenesis: synoptic study of two cases occurring during ALPEX Special Observing Period. Scientific results of the alpine experiment (ALPEX), WMO/TD 108: 297-308.

Jarraud, M., A. Simmons and M. Kanamitsu. 1987. The concept, implementation and impact of an envelope orography. ECMWF, 81-128.

Mason, P. J. 1987. On the parameterization of orographic drag. ECMWF: 167-194.

Mason, P. J. 1988. The formation of areally-averaged roughness lengths. Quart. J. Roy. Met. Soc. 114: 399-420.

Messinger, F., and Z. I. Janjic. 1987. Numerical techniques for the representation of mountains. ECMWF, 29-80.

Miller, M. J., and T. N. Palmer. 1987. Orographic gravity wave drag: its parameterization and influence in general circulation and numerical weather prediction models. ECMWF, 283-333.

Nickerson, E. C., E. Richard, R. Rosset and D. R. Smith. 1986. The numerical simulation of clouds, rain and airflow over the Vosges and Black Forest Mountains: A meso- $\beta$ model with parameterised microphysics. Mon. Wea. Rev. 114: 398-414.

Palmer, T. N., G. J. Shutts and R. Swinbank. 1986. Alleviation of a systematic westerly bias in general circulation and NWP models through an orographic gravity wave drag parameterization. Quart. J. Roy. Soc. Met. 112: 1001-1039.

Petitdidier, M., V. Klaus, F. Baudin, M. Crochet, G. Penazzi and P. Quinty. 1986. The INSU and DMN network of ST radars. Handbook for MAP, 20: 347-348.

Pierrehumbert, R. T., and B. Wyman. 1985. Upstream effects of mesoscale mountains. J. Atmos. Sci. 42: 977-1003.

Ramis, C., and M. Ballester. 1984. Cyclogenesis catalon-balear. Estudio del temporal de abril de 1978. Revista de Geofisica 40: 243-258.

Richard, E., P. Mascart and E. C. Nickerson. 1989. On the role of surface friction in downslope wind storms. I. Appl. Meteor. 28: 241-251.

Richner, M. 1987. The design and operation of a microbarograph array to measure pressure drag on the meso-scale. J. Atmos. Ocean. Tech. 4: 105-112.

Riosalido, R., L. Vazquez, A. Gordo and A. Jansa. 1986. Cierzo: a northwesterly wind along the Ebro valley as a mesoscale effect induced on the lee of the Pyrenees mountain range: a case study during ALPEX Special Observing Period. Scientific results of the alpine experiment (ALPEX), WMO/TD 108: 565-576.

Royer, J. F., and O. Clary. 1987. Paramétrisation linéaire des ondes de gravité dans un modèle de circulation générale de I'atmosphère. AMA 87: 108-120.

Smith, F. B., and D. J. Carson. 1977. Some thoughts on the specification of the boundary layer relevant to numerical modelling. Bound. Layer Meteor. 12: 307-330. 
Smith, R. B. 1979. The influence of the earth's rotation on mountain wave drag. J. Atmos. Sci. 36: 177-180.

Stein, J. 1989. Numerical study of two cases of hydrostatic flow over the Pyrénees (in French). ENM Internal Report no. 271, 190 pp. (available from CNRM).

Talagrand, O., and P. Courtier. 1987. Variational assimilation of meteorological observations with the adjoint vorticity equation. Part I: Theory. Quart. Jour. Roy. Meteor. Soc. 113: 1311-1328.

Viers, G. 1960. The meteorological events of 1959 in the Pyrénees (in French). Rev. Geogr. Pyr. S.O. pp. 109-112.

Viers, G. 1987. Observations on thermal effects of Foehn in Pays Basque (in French). Publications of the Geographical Institute of Clermont-Ferrand, no. 65 (available from University of Clermont 63170 Aubiere).

WMO. 1986. Scientific results of the Alpine experiment. GARP publication series no. 27, (2 volumes) available from WMO secretariat case postale no. 5, CH 1211 Geneva 20, Switzerland).

\section{announcements}

\section{International Workshop on Large Eddy Simulation}

The international workshop "Large Eddy Simulation-Where do we Stand?" will be held 19-21 December 1990 in St. Petersburg, Florida. For further information, contact Boris Galperin, Department of Marine Science, University of South Florida, 140 Seventh Avenue South, St. Petersburg, FL 33701, (813) 893-9101.

\section{Climate Diagnostics Workshop}

The 15th Annual Climate Diagnostics Workshop will be held 29 October-2 November 1990, in Asheville, North Carolina. The Workshop is sponsored by the Climate Analysis Center, National Meteorological Center, NOAA/ NWS and is cosponsored this year by the National Climatic Data Center NOAA/NESDIS. Regional and global climate fluctuations for the year ending August 1990 will be a focus of the workshop. The workshop will also address research and diagnostic studies of large-scale ocean-atmosphere interaction including intraseasonal to interannual variability; early detection and prediction of warm and cold southern oscillation episodes; and climate prediction on monthly and seasonal temporal scales. A special session will focus on datasets for detection of global climate change.
A poster session will be scheduled to highlight climate data and services provided by the CAC, NCDC, and Regional Climate Centers. Those interested in participating in the workshop should contact David Rodenhuis, Climate Analysis Center W/NMC5, Rm 604 World Weather Building, Washington DC 20233, (301) 763-8167 by 1 August 1990.

\section{International Workshop on Urban Rainfall and Meteorology}

The International Workshop on Urban Rainfall and Meteorology will be held 2-5 December 1990 in St. Moritz, Switzerland. This conference is supported by $\mathrm{WMO}$, and IAHS. For more information, contact Glenn E. Stout, Secretary-General, International Water Resources Association, 205 North Mathews Avenue, Urbana, Illinois 61801-2397, (217) 333-6275

Notice of registration deadlines for meetings, workshops, and seminars, deadlines for submission of abstracts or papers to be presented at meetings, and deadlines for grants, proposals, awards, nominations, and fellowships must be received at least three months before deadline dates. - News Editor 